\title{
TENSIONES Y EVASIONES EN LAS PRÁCTICAS DE LECTURA DURANTE EL SIGLO XIX A PARTIR DE LA FORMACIÓN LECTORA DE MARTINA BARROS DE ORREGO EN RECUERDOS DE MI VIDA ${ }^{1}$
}

\author{
Tensions and evasions in Reading practices during the nineteenth century as from \\ the reading education of Martina Barros de Orrego in Memories of my life
}

\author{
Damaris Landeros Tiznado* \\ Edda Hurtado Pedreros**
}

\begin{abstract}
RESUMEN
En el presente artículo se analizará la memoria de Martina Barros, Recuerdos de mi vida (1942), específicamente las instancias de formación intelectual que corresponden a su infancia y juventud. Para ello, y considerando el carácter relevante que tendrá "la escena de lectura" en las autobiografías de escritores hispanoamericanos (Molloy, 2001), el principal material de análisis serán las representaciones de estas prácticas y las características de la autofiguración de esta lectora en específico, considerando las constricciones padecidas en su desarrollo intelectual por las mujeres durante el siglo XIX y el XX. Observaremos también la importancia del nexo patrilineal -sobre todo con su tío Diego Barros Arana-y el enlace matrimonial en su formación intelectual. Para ello, y considerando las características de este tipo de género -escrituras del yo (Miraux, 2005)- se desprenderán las particularidades de esta experiencia subjetiva femenina en el proto-campo literario chileno en los albores del siglo XX.
\end{abstract}

Palabras clave: Martina Barros, mujeres escritoras, prácticas de lectura, autobiografía, literatura chilena, siglo XIX.

\footnotetext{
${ }^{1}$ Este artículo se enmarca en el Proyecto Fondecyt Postdoctoral $2016 \mathrm{~N}^{\circ}$ 3160589: "Lectoras y lecturas: la escenificación de la lectura en autobiografías de mujeres escritoras (1890-1935)" a cargo de Damaris Landeros y del DI Regular PUCV 37.0/2017, "La conformación del Castellano como disciplina escolar: literatos pedagogos, canon literario y manuales de lectura entre 1890 y 1930" correspondiente a Edda Hurtado.

* Facultad de Filosofía y Educación, Instituto de Literatura y Ciencias del Lenguaje, Pontificia Universidad Católica de Valparaíso. Valparaíso, Chile. Correo electrónico: damaris.landeros@, hotmail.com

** Facultad de Filosofía y Educación, Instituto de Literatura y Ciencias del Lenguaje Pontificia Universidad Católica de Valparaíso. Valparaíso, Chile. Correo electrónico: eda. hurtado@pucv.cl
}

Artículo recibido el 17 de abril de 2018. Aceptado el 08 de octubre de 2018. 


\begin{abstract}
In this article we will analyze the memories of Martina Barros Recuerdos de mi vida (1942), specifically the instances of intellectual formation that correspond to the author's childhood and youth. For that, and considering the relevant nature of "the reading scene" in the autobiographies of Spanish-American writers (Molloy, 2001), the main analysis material will be the representations of these practices and the characteristics of the autofiguration of this reader in particular, mainly considering the constrictions suffered in terms of intellectual development by women during XIX and early XX centuries. Thus, we will be able to observe the importance gained by patrilineal nexus -specially with her uncle Diego Barros Arana- and then by her marriage in her intellectual formation. For that, and considering the characteristics of this genre -writings of the self (Miraux, 2005)-, the peculiarities of this female subjective experience in the Chilean proto literary field of early XX century will be detached.
\end{abstract}

Keywords: Martina Barros, women writers, reading practices, autobiography, Chilean literature, XIX century.

"Mucho he trepidado antes de resolverme a realizar este deseo tan largo tiempo acariciado. Me parecía vanidoso suponer que en mi vida

hubiese algo que mereciera recordarse; pero me daba a mí misma como excusa que bien valía la pena narrar las transformaciones que he presenciado en la sociedad, y recordar las personas ilustres que me ha tocado en suerte conocer".

Martina Barros, 1942.

\title{
1. Consideraciones preliminares sobre la escritura de autorrepresentación
}

La literatura hispanoamericana recuerda, sostiene Sylvia Molloy (2001) aduciendo a la proliferación de las escrituras del yo en la tradición literaria hispanoamericana. La escasa consideración del funcionamiento del proceso de recordar ha relegado a estas escrituras a un uso utilitario, y su análisis demanda el estudio de la posición del testante, en tanto: "[...] el presente de la escritura sin duda condiciona el rescate del pasado; no cuenta tanto lo recordado sino cuándo se recuerda y a partir de dónde" (186). La 
tradición en la que se inscribe Martina Barros con sus Recuerdos de mi vida (1942) corresponde a la decimonónica hispanoamericana, periodo en el que, según Molloy, el concepto que se tiene de la autorrepresentación en la escritura se asume principalmente como documento histórico y así han funcionado esos textos para la historiografía literaria contemporánea², es decir: “[...] la verdad objetiva, la utilidad y el valor didáctico justifican la narración de una historia personal, y garantizan su mérito documental" (189). La tradición de escrituras del yo en el siglo XIX representaba un medio de transmisión de la historia de las naciones emergentes. Si bien Recuerdos de mi vida se inscribe en esa tradición, en este trabajo nos interesa explorar las vacilaciones en torno a la validez de la escritura que la autora le asigna, en tanto se trata de una mujer que escribe y que se presenta a sí misma como una protagonista lateral del escenario letrado. Su propósito - vacilante al escribir- se resuelve a partir del deseo de dar cuenta de episodios que ha vivido e inscribe en un contexto mayor, relacionado con la historia nacional chilena:

Mucho he trepidado antes de resolverme a realizar este deseo tan largo tiempo acariciado. Me parecía vanidoso suponer que en mi vida hubiese algo que mereciera recordarse; pero me daba a mí misma como excusa que bien valía la pena narrar las transformaciones que he presenciado en la sociedad, y recordar las personas ilustres que me ha tocado en suerte conocer (Barros, 1942: 10).

A partir de este deseo personal, la autora fija su ambivalencia entre un 'yo' que duda de su importancia como cronista y un 'contexto' que justifica su pertinencia como relatora. Barros narra su historia, entrecruzando hitos personales y sociales, estableciendo una precaria cronología de su vida articulada con las transformaciones de las que fue testigo. Sus recuerdos emergen para reconstruir una particular memoria que se segmenta a partir de los principales hitos de su vida -infancia, juventud, matrimonio y últimos años-, pero remitiéndolos a pasajes relevantes del relato nacional, vinculándolos a procesos históricos relevantes tales como "El Incendio de la

\footnotetext{
${ }^{2}$ Para el caso de la literatura chilena cabe mencionar el texto señero de Gonzalo Catalán, "Antecedentes sobre la transformación del campo literario en Chile entre 1890 y 1920", en José Joaquín Brunner y Gonzalo Catalán: Cinco estudios sobre cultura y sociedad. FLACSO: Santiago, 1985.
} 
Compañía", "La Guerra con España", la "Revolución de 1891". Más allá de una segmentación entre los episodios nacionales y los íntimos, lo cierto es que la división no escinde del todo ambas esferas. Vida íntima y contexto social se vinculan indisolublemente en el relato. Silvia Molloy (2001) desarrolla el común carácter ambivalente de los textos autobiográficos latinoamericanos, afirmando que: “[...] la vacilación entre persona pública y yo privado, entre honor y vanidad, entre sujeto y patria, entre evocación lírica y registro de los hechos, son solo algunas de las manifestaciones de la vacilación que caracterizó (y acaso sigue caracterizando) la escritura autobiográfica en Hispanoamérica" (15). Estos saltos entre heterogéneas dimensiones, sobre todo aquellas que transitan en el espacio público y el privado, permiten dar cuenta de un panorama de la realidad social en la que se enmarcan el discurso y la autora, estableciendo su aparente relevancia en el escenario literario y social del Chile decimonónico. Junto con este problema propio del entramado discursivo que caracteriza al texto autobiográfico, otro elemento importante a considerar en dicho texto es la verosimilitud, sobre todo al percatarse de que esta será el material fundamental para estudiar las diversas prácticas de lecturas escenificadas, además de darnos indicios de las diversas apropiaciones culturales realizadas durante la segunda mitad del siglo XIX. Las autobiografías parecieran ser el material menos indicado para precisar las prácticas de lectura efectivas, en tanto ellas siempre estarán mediadas por juicios, omisiones y, en general, por la subjetividad del/la narrador/a. Ahora bien, y siguiendo lo propuesto por Roger Chartier (2006), pensar el ejercicio de historizar -en este caso, poner en valor las prácticas de lectura a partir de este 'documento'-, siempre implica la mediación de una subjetividad, la que no puede sino estar construida desde una perspectiva signada por la ideología de quién narra. Por lo mismo, creemos que el ejercicio de auto-representación -en este caso de las prácticas de lectura- más que constituirse como un corpus inadecuado para analizar, nos permite comprender de una forma más directa desde dónde provienen esos sesgos, omisiones y juicios, en tanto hace evidente el carácter personal del discurso. Jean Philippe - Miraux (2005) establece que este es uno de los más relevantes dilemas al momento de analizar este tipo de discursos: la 
sinceridad del escritor puede verse perjudicada por el olvido, pero también por el pudor de sus errores o, finalmente, por el deseo de proyectar(se) como no es. Citando al autor: "[el escritor] por dictado de su yo interior, al sumergirse en el impreciso mundo de los recuerdos, [requiere] encontrar la tonalidad justa, el registro pertinente, susceptible de dar cuenta -a veces de ajustar cuentas- de la trayectoria de una vida" (11). Es así como la articulación entre lo escurridizo que se torna la verdad en Barros -o las verdades- y los impulsos de fijar la mejor versión posible de sí misma, crean un texto de naturaleza ambivalente, pero rico en representaciones verosímiles del mundo objetivo.

\section{Devenir letrada: avatares biográficos y capital cultural}

Martina Barros (1850-1944) tuvo una larga vida, siendo agente culturaly testigo relevante de una época de cambios fundamentales en el escenario letrado chileno, donde alcanza un rol preponderante en la escena intelectual, sobre todo femenina, siendo considerada como una de las participantes nacionales más destacadas de lo que se denominará el "Feminismo Liberal" (Castillo, 2009; Traverso, 2012), una línea que busca la obtención de derechos sociales como el sufragio femenino, además de reivindicaciones intelectuales para las mujeres. Y aunque en sus primeros escritos ${ }^{3}$ ella reniegue de la importancia que dan sus congéneres al derecho a voto, posteriormente es posible observar que estas reivindicaciones mencionadas serán claves al estudiar su producción intelectual. Sin embargo, no fue solo por su discurso, sino también por su locus de enunciación que esta intelectual destacó. Al establecer su filiación patrilineal, refiere la casa del abuelo, su ubicación y, luego, al mencionar al padre, resalta las coordenadas espaciales en su descripción aunque con mediación afectiva: "La casa era relativamente pequeña, al menos la primera que recuerdo, que estaba situada en la esquina de Huérfanos con Bandera frente al costado de la de Matías Cousiño, que ocupó después, por muchos años el Club de la Unión" (35). Cabe precisar que Lorena Amaro en su artículo "Encuadres de la Memoria: Cartografías y genealogías en los textos de Martina Barros e Inés

\footnotetext{
${ }^{3}$ Nos referimos específicamente al prólogo que realiza a la obra de John Stuart Mill La esclavitud de la mujer (traducción publicada por entregas en la Revista de Santiago en 1872).
} 
Echeverría" (2013), reparó en este aspecto, concluyendo, a nuestro parecer acertadamente que: "[...] las memorias de Barros indudablemente hablan de eso: de una cultura, de un espacio vivido y transformado, de unos valores compartidos con las personas de su clase y condición" (145). Debido a esto, sostiene Amaro:

Las precisiones sobre los lugares -que son, al fin y al cabo, lugares neurálgicos de la nación, en que se desarrollarán la política y la economía republicanas (bancos, clubes, iglesias) - van acompañadas de otras, sobre los antepasados y familiares ubicados a lo largo de esa trama. Ahora bien, estos encuadres a veces son más limitados: se ven recortados por su condición femenina y, por lo tanto, "impresionable": desobedeciendo a los mandatos familiares, observa desde un postigo entreabierto el desfile de carretas con los cadáveres carbonizados de la víctimas del incendio de la Compañía (principalmente mujeres), o bien, desde otra rendija igualmente bien ubicada, el ajusticiamiento de un reo en Valparaíso (145).

Esta segunda perspectiva - la mirada oblicua que Amaro refiere- es importante en este estudio, pues a pesar de pertenecer a una clase social privilegiada, Martina es marginada debido a su "condición femenina", lo que se traducirá en un posicionamiento cuya focalización difiere de la de los memorialistas varones, centrados en los grandes hechos sociales, manifestando una posición privilegiada y objetiva de los mismos. Esta posición liminal -privilegiada/marginada- a su vez se manifiesta en uno de los espacios más representativos de la confluencia de las esferas de lo público/ privado, nos referimos al salón, lugar en el que Barros destacó como una de las principales salonnière de su época. Estos espacios de sociabilidad intelectual decimonónica ${ }^{4}$ favorecieron en Martina el acceso a círculos y redes de los intelectuales más respetados de su época, logrando una posición como interlocutora válida, a pesar de haber recibido estudios formales solo hasta los 12 años. Entendidas como instancias de 'formación complementaria' llegarán incluso a suplantar otras más legitimadas en términos institucionales. A temprana edad, Barros ingresó a una pequeña escuela dirigida por Rafaela Fernández, donde aprendió a leer y escribir. Luego fue al colegio de M. Leboeuf,

\footnotetext{
${ }^{4}$ También gracias a la temprana participación en los salones y tertulias de su tío Diego Barros Arana, los de su esposo Augusto Orrego Luco y su propio salón.
} 
para finalmente ingresar al colegio de Miss Whitelock cuando recién contaba con cinco años de edad. Allí permanecerá hasta los doce. Y aunque recuerda esta última experiencia escolar con alegría, sostiene que: “[...] aprendí en realidad pocos conocimientos" (58). Claramente la escuela -gran proyecto modernizador del siglo XIX - no constituye para la niña Martina Barros una instancia formadora fundamental ni tampoco es asimilable a la experiencia intelectual que el Instituto Nacional tempranamente significó para los varones de la elite. En su caso, la escolarización fue menos significativa y el acceso a los conocimientos provino de instancias extra-escolares, de espacios de sociabilidad intelectual directamente vinculados al ámbito familiar y de los afectos. Desde donde emerge y se constituyen su distinción simbólica y su desarrollo intelectual. Al respecto sostiene:

En mi caso la ilustración se la debo a mi tío Diego [Barros Arana] que cuidó de ella mientras permanecí soltera, creo que no habría sido posible encontrar un mejor maestro; y de casada, a mi marido [Augusto Orrego Luco] que era un espíritu superior y que supo guiarme en eso, como en todo, admirablemente; y alguna pequeña parte debo también a mi propia iniciativa, a mi afán de conocimientos, a mi admiración por el talento superior, que ha sido una de las características de mi vida (59).

A pesar de recibir solo nueve años de escolaridad, su educación fue privilegiada en comparación con sus congéneres, sin embargo, es debido a su habitus de clase (Bourdieu, 2011) -más que a una formación intelectual sistemática- que se produce su validación en los selectivos círculos de la intelectualidad nacional: una "genealogía patrilineal" (Traverso, 2012) y una participación en espacios liminales como los salones y las tertulias. Este capital cultural será el que más tarde le permita aceptar la petición -por parte de su futuro marido Augusto Orrego Luco- de traducir el texto de John Stuart Mill (1806-1873) The subjection of women (1869), con el fin de ser publicado en la Revista de Santiago (1872-1873), en su primer año de circulación. La tarea de traducción implicaba, además, un prólogo introductorio a la obra realizado por Barros, lo que le significó una excelente recepción por parte del público masculino. Ahora bien, no todo el reconocimiento fue positivo, pues la lectura que hicieron sobre todo sus congéneres pertenecientes a las familias de la elite 
capitalina, evidenció el reverso de la formación intelectual femenina, lo que decantó en graves consecuencias para su vida personal y su carrera literaria: “[...] continué mi vida, entregada por entero a mis afectos más hondos, pero sin volver a hacer publicaciones que no convencían ni alentaban más que a los ya convencidos y causaban pavor a aquella que deseaban estimular" (127). Si bien continuará participando en instancias de sociabilidad consideradas en retrospectiva como precursoras de círculos proto-feministas ${ }^{5}$, en las primeras décadas del siglo $\mathrm{XX}$, su mutismo escritural ${ }^{6}$ al que se verá relegada, será interrumpido principalmente con la escritura y posterior publicación de sus memorias en el año 1942, dos años antes de su muerte. Por esta razón, la obra de Martina da cuenta de las luchas, retrocesos y avances que ocurrieron durante este periodo en el ámbito nacional, poniendo en valor la necesidad de conocer la historia de una testigo de época, ciertamente privilegiada.

\section{El recuerdo selectivo: la escuela y la casa como instancias de formación lectora}

En el diario íntimo de Martina Barros encontramos una serie de escenas en las que la lectura cobra valor como práctica de formación intelectual y espiritual. A pesar de haber practicado la escritura tempranamente, tuvo que relegarse al anonimato de la vida privada producto de los efectos que produjo

\footnotetext{
${ }^{5}$ Como ya hemos sostenido, su presencia en diversas instancias de sociabilidad es clave, pero destaca sobre todo su participación en las conferencias dadas en el Club de Señoras. Es importante recordar que la importancia de este club radicaba en la capacidad de tener un espacio, alejado de la casa, en el que las mujeres pudieran: "[...] procurarse todos los placeres intelectuales y sociales que no es fácil obtener de otra manera" (Barros, 1942: 290). Es así como la autora expone en cuatro oportunidades en este espacio: en la primera se preocupó del sufragio de las mujeres en su ensayo El voto femenino (1917); en la segunda, sobre la problemática autoral de Shakespeare llamada ¿Quién es el verdadero autor de las obras de Shakespeare? (1923); el tercero, trata sobre el Escorial de Felipe II (temática motivada por su viaje a España) (1926) y, finalmente, su última conferencia trataba sobre las más importantes mujeres de la época, Mujeres de mi tiempo, que coincide con uno de los últimos apartados de sus memorias, denominado Mujeres de mi tiempo (306-348).

${ }^{6}$ Cabe hacer una aclaración en este punto, pues existen publicaciones y escritos de Martina posteriores a la traducción de Stuart Mill, siendo el más importante el estudio ensayístico Felipe II y el escorial editado en 1926 a raíz de la tercera conferencia desarrollada en el Club de Señoras. También es posible encontrar en la Revista chilena (1917) la publicación de la conferencia antes dictada en el Club de Señoras, El voto femenino. Ahora bien, su publicación corresponde a folletos de baja circulación o publicaciones agregadas a otros medios como revistas, los que han sido tradicionalmente considerados con menor peso intelectual. En relación a este tema se recomienda el estudio de Joyce Contreras La resistencia al libro. Mujeres, escritura y exclusión en el siglo XIX en Chile (2014).
} 
en sus pares la experiencia de la publicación del texto de Stuart Mill. Es por ello que las ocasiones en que se describe la práctica escritural dentro del texto autobiográfico son escasas, contraponiéndose a la prevalencia que cobrarán las escenas de lectura. En sus palabras, la lectura: "[...] ha sido siempre mi afición predilecta" (Barros, 1942: 143). Irónicamente, las primeras menciones a esta práctica no son del todo gozosas, en tanto ellas estaban signadas por la imposición y el miedo. En la primera parte de sus memorias, se describe la lectura referida por primera vez, pero esta será de oídas - esto porque Barros no sabía decodificar los textos-, pero tempranamente esto muta a una lectura impuesta:

Más tarde cuando estaba más crecidita y sabía leer, lo que fué muy temprano, recuerdo que mi madrina hacía que le leyere estos libros [el Año Cristiano, la vida de Jesucristo y otros libros de devoción] todos los días, y a veces, por la noche en alta voz, los Salmos de David. Esta lectura era para mí el suplicio más atroz, y como no me atrevía a confesarlo, inventaba siempre dolores de muelas para sustraerme a aquel tormento (23).

Este consumo impuesto contrasta con una lectura espiritual, intensiva y beneficiosa que se pretende desarrollar con la lectura de los "libros de devoción", buscando la comunión entre la narración y el lector, para nutrir y alimentar el espíritu. Esta lectura, por el contrario, genera el "suplicio más atroz" y "angustia del alma", tanto así que la autora prefería buscar ardides para evitarla. Este encuentro con el libro va a diferir profundamente de otros encuentros que la autora narrará, sin importar si ellos también son impuestos $\mathrm{y}$ vigilados.

Desde el inicio de su educación formal, la primera habilidad que se representa es la adquisición de la lectura, contextualizándola en el espacio de la casa de misiá Rafaelita, una mujer instruida que encontraba el sustento familiar $^{7}$ en la educación inicial de los niños. Esto queda en evidencia cuando

\footnotetext{
${ }^{7}$ El carácter no profesional de las docentes fue muy común hasta 1860 -año en que se promulga la Ley Orgánica de Instrucción Primaria-hecho que permitirá cubrir y desarrollar de mejor forma la educación de las mujeres, buscando, entre otras cosas, una mayor instrucción de las preceptoras. En palabras de María Loreto Egaña: "[...] las niñas eran educadas por preceptoras que tenían y trasmitían menos conocimientos y carecían de formación pedagógica que, en cambio, empezaban a tener los preceptores varones" (2000: 97).
} 
la testante describe con detalle las particularidades del espacio en el que se realizaban las clases:

[...] en un extremo, sobre una mesa, los catones, que así se llamaban los silabarios; yo aprendí a leer en un Catón cristiano. Junto a la ventana estaba la silla de brazos de madera ordinaria con asiento de paja, que ocupaba misia Rafaelita y al lado, en el suelo, un gran cajón con los punteros. Eran éstos unos palitos cortos y redondos, aguzados en la punta como un lápiz, que nos servían para apuntar la letra que pronunciábamos (51).

El espacio descrito es simple y sin grandes lujos, marcado por la presencia de una figura de autoridad, representada por esta: "silla de brazos de madera ordinaria y asiento de paja", y por las herramientas didácticas que regulaban las prácticas educativas. Nada se señala en torno a cómo eran los asientos de los estudiantes, ni en qué condiciones se adaptó la casa familiar para las labores educacionales. Los catones y punteros evocados serán de suma importancia para decodificar los signos escritos. El primero, especifica que era cristiano a diferencia de otro tipo de libros para la enseñanza de la lectura. El segundo, es un instrumento que cumplía una doble función: enseñar a decodificar las letras e instruir sobre los códigos y preceptos cristianos. Por ello, en estos libros no es extraño encontrar oraciones, enseñanzas e imágenes propias de la iconografía católica acompañando las iniciales uniones silábicas y repeticiones de fonemas propios de esos textos. El puntero también señalará e indicará lo que se lee, visibilizando una práctica que puede parecer solo mental y abstracta. El puntero guía la lectura del estudiante, evitando 'perderse', pero también hace visible para el docente la práctica, corrigiendo y castigando ( $\mathrm{si}$ fuese necesario) la fuga, modificación y error, procurando la normalización de la praxis lectora. Ambos objetos disciplinan la lectura -ejercicio común en la escuela-, favoreciendo la reproducción del sentido literal; la triada catón, maestro y alumno/a entran en tensión durante la enseñanza. La maestra guía la lectura del catón, el que primero es un tablero indescifrable para luego pasar a convertirse en una serie de signos con sentidos fijos e impuestos. La niña Martina debe indicar con el puntero estos signos, decodificándolos y respetando las normas propias de la cultura escrita, para que sea calificada 
positivamente.

La calificación y evaluación de las prácticas de lectura también se observa en un episodio posterior narrado por Barros, cuando describe un concurso de lectura desarrollado por la escuela de M. Leboeuf:

\begin{abstract}
Recuerdo con emoción aquel examen, el único de mi vida. Todas las chiquillas estábamos sentadas en una gran sala y desde un extremo de ésta, junto a una mesa, los examinadores indicaban el nombre de la niñita que debía leer. A mi lado estaba Mariana Urmeneta que, a mi juicio, era la que leía mejor. Le tocó su turno y leyó muy bien y con toda tranquilidad. En seguida sonó mi nombre y a mí me zumbaron los oídos y me corrió frío por la piel; sin embargo, me dominé y leí lo mejor que pude. Mi sorpresa fue grande después cuando supe que me habían otorgado el premio, quizás en vista de mis pocos años. Este consistía en un libro: el Manual de Urbanidad que yo conocía. Como los libros no eran para mí para mirarle las tapas y las láminas, porque mi papá se preocupaba mucho de hacerme leer y de que le explicase lo que leía, no quise quedarme con uno que ya conocía y fui a decírselo a M. Leboeuf, quien me escuchó muy complacido y me presentó otro muy bien empastado preguntándome si bien lo conocía. Era este El Coloquio de los Perros de Cervantes, que acepté con mucho gusto porque mi papá me contaba siempre episodios del Quijote y sabía quién era Cervantes. Mis compañeras me embromaron mucho, me acuerdo, porque este libro no tenía láminas como el que yo había desechado (52-54).
\end{abstract}

La lectura a viva voz era necesaria para poder establecer de qué modo las pausas, énfasis y entonaciones eran llevadas a cabo, normas que quedaban invisibilizadas y silenciadas en el consumo personal. A su vez, la lectura era un ejercicio muy vinculado al cuerpo, sobre todo en los siglos XVIII y XIX (Littau, 2008), por lo que el análisis de la lectura en voz alta era fundamental a la hora evaluar esta práctica en todas sus dimensiones. En esta calificación el sentido del texto tiene un valor menor, pues la lectura es un ejercicio físico, visible, en el que se conjugan todos los componentes de la oralidad-verbales, paraverbales y no verbales- a la hora de establecer a los vencedores, lo que se puede observar incluso en que la interpretación es rastreable a través de los gestos, modos y entonaciones que se observan y escuchan, primando lo corporal por sobre lo mental.

Por otra parte, el cambio de un libro ilustrado por otro sin ilustraciones, Martina lo justifica a través de la función que le da a la lectura (descifrar sentidos), lo que representa un modo de lectura, más cercano a la intensividad, 
tradicionalmente considerada como masculina y propia de un lector ya más consolidado, que a la extensividad moderna, lo que trae como consecuencia la respuesta burlesca por parte de sus compañeras. Finalmente, dentro de las instancias institucionales de formación de esta lectora, la de la escuela de Miss Whitelock, a la que ingresa en marzo de 1856, será la que le proporciona una relación más gozosa con el aprendizaje:

[Miss Whitelock] Despertó en mi alma el sentimiento de lo bello y me acostumbré a buscarlo y descubrió en la naturaleza, en el arte y en el alma humana [...] Nos inculcó a todos un grande amor por todo lo inglés: su lengua, su literatura, sus costumbres, la política, sus grandes hombres y sobre todo, por su Reina a quien idolatraba (57).

Y aunque este conocimiento, en sus palabras, fue "poco" (58), su carácter formativo será clave para el resto de su vida. A su alero aprenderá de labores de mano, la importancia de la higiene postural -Miss Whitelock vigilaba el "leer sin agacharnos" (56)-y, por sobre todo, el idioma inglés, aprendizaje clave en el futuro de su historia.

En términos espaciales, Martina reanuda sus estudios en el escritorio de su tío Diego Barros Arana, luego de que su educación formal concluyera a los 12 años. Allí Barros Arana fomentó el desarrollo de las principales habilidades de una joven Martina: lectura, escritura y oralidad, sobre todo la primera, a través del préstamo y obsequio de textos que siempre estuvieron acompañados de una práctica pedagógica -disciplinada y regulada- que desarrollaba Barros Arana con su sobrina. Es así como ella narra este ejercicio:

Se preocupó ante todo de la educación de mis hermanos, que fueron colocados internos en el Instituto Nacional y, como yo quedé viviendo a su lado y mi instrucción era muy deficiente, puso gran empeño en dirigirla haciéndome estudiar historia que leía, con detención, todas las mañanas. Primero la historia antigua y griega y después la romana de Duruy, y en seguida, durante el almuerzo me hacía preguntas sobre lo que había leído y me explicaba con claridad extraordinaria todo lo que yo no entendía bien. Así, poco a poco, haciéndolo agradable despertó en mí la afición por el estudio. Siempre me obsequiaba libros instructivos y amenos que me ilustraban en las bellas letras. Recuerdo especialmente una colección, en varios tomos, de extracto de todos los poemas clásicos, desde Homero, a nuestros tiempos, biografías de todos los grandes hombres del mundo, noticias de los principales descubrimientos científicos y geográficos, etc., una verdadera enciclopedia muy interesante y que ha sido la base de mis conocimientos (Barros, 69). 
Junto con colaborar en la formación de Barros con textos que constituirán la base de sus conocimientos, su tío pedagogo vigila el corpus de consumo lector al seleccionar los textos regalados -instructivos y amenos- lo que puede ser pensado como un pequeño programa de estudio, que incluía 'asignaturas' poco comunes para las mujeres (historia laica, literatura e incluso ciencias). Del mismo modo, Barros Arana procuraba generar un hábito y desarrollar una metodología pedagógica adecuada para la educanda:

Con frecuencia me hacía leerle en alta voz y me corregía todos los inevitables errores de un niño, lo que le he agradecido mucho, pues sin un ejercicio metódico no se aprende a leer. En otras ocasiones me tomaba de escribiente, más para descansar, porque era un escritor infatigable, para ver mi letra y ortografía a la que atendía mucho, explicándome el por qué era necesaria (70).

Diego Barros Arana desempeñó un rol pedagógico con sistematicidad y rigurosidad vigilante de las prácticas lectoras y escriturales, ejerciendo su autoridad a través de la corrección, la acción disciplinaria y normativa por excelencia; la lectura en voz alta se enfatizaba como una estrategia para que el mentor pudiera intervenir y corregir, insistiendo en las formas y gestos de la alumna ${ }^{8}$, procurando también enfatizar en la adquisición de sentidos a través de las preguntas. En esta metodología se busca regular en la niña lectora los modos de leer y de construir significados, insistiendo en el sentido literal de la obra e impidiendo lecturas más subversivas del texto. Si consideramos a esta forma de interpretar como el índice y producto de una élite social (Certeau, 2007: 183-185) cristalizado por los 'sabios', oponerse al mismo es un modo de transgredir ese orden que imponía el elenco letrado a través de la vinculación relaciones de poder/saber-casi exclusiva que ellos tenían con las instituciones reguladoras del conocimiento (universidades, liceos, Ministerio de Instrucción

\footnotetext{
${ }^{8}$ Utilizamos esta palabra rescatando el sentido original del latín alumnus que significa alimentado. La concepción de educación que existe en el periodo al que hacemos referencia, y que prevalecerá por gran parte del siglo XX, tiene este sesgo que es el de una acción padecida - un consumidor- la que se condice con la escenificación que hace Barros de su relación con el orden masculino, representado en las figuras que le proveerán de 'alimento' durante su educación no formal. Para profundizar este tema recomendamos el texto de Karin Littau Teorías de la lectura. Libros, cuerpos y bibliomanía (2006).
} 
Pública, etc.). A pesar de este poder censor/ regulador de interpretación que ejercía su tío, es en su compañía que comenzó a descubrir el real placer por la lectura con el acceso a textos formativos estrictamente vigilados, hasta llegar a textos literarios y filosóficos de mayor complejidad. Barros Arana encontró en ella una alumna aplicada y Martina encontró en él un medio para acceder a pensamientos, ideas y discursos a los que no hubiese accedido dada su escasa formación escolar. Es por esto que, a pesar de no haber egresado de bachiller, su educación no puede etiquetarse como precaria y se produjo en un entorno familiar, confirmando otros modos de acceso a la cultura letrada.

\section{Seducción y engaño a través de la lectura}

El momento en que Martina Barros logró mayor conexión con los textos literarios fue en su juventud mediante la relación poético/amorosa que construyó con su futuro esposo, Augusto Orrego Luco. La afinidad se fue implantando en consonancia con las ideas e interpretaciones en esta lectura dialogada y en pareja. En la descripción de cómo se fue asentando la alianza amorosa, se destaca lo enfática que es Barros al declarar que, si bien las primeras veces que lo observó no hubo de su parte atracción, ella se fue construyendo paulatinamente:

Desde que se sentó a mi lado, me sedujo con su palabra fácil y elocuente y con su ilustración, que me pareció extraordinaria. Al regresar a mi casa le dije entusiasmada a mi mamá: "Aquel raro que divisábamos en el balcón es todo un hombre, con talento, elocuencia y erudición, con maneras finas y nada retraído, como lo creíamos" (120).

En la descripción del encuentro inicial, la vista es reemplazada por el oído, pues las impresiones iniciales son modificadas luego de que ella lo escucha, reemplazando las características anteriores -raro y retraído- por otras que ahora considera más acertadas -maneras finas-. Sin embargo, este no será un amor 'a primera vista', por el contrario, ella sabe que siente admiración, pero que se encuentra "lejos del amor" (121). Durante el periodo anterior al noviazgo, entablaron conversaciones e intercambiaron libros, recomendándose autores para, posteriormente, comentarlos, generando un 
nexo similar a los Redding clubs (Oses, 2012). Él la respetaba como lectora y aunque la relación no era del todo simétrica, Barros se sentía validada en su condición de estudiosa. Este nexo intelectual se interrumpe en el momento en que Orrego le facilita, a pedido de Martina, algunos de sus cuentos propios en los que inserta una especie de declaración amorosa al citar, supuestamente, a Petrarca. Al descubrir los tintes que esta relación podía cobrar, Barros decide hablar con él e intentar frenar los sentimientos que identificaba en él. Muy a su pesar, le expresó que no lo correspondía y que en ese momento solo sentía una hermosa amistad. La narración de esta anécdota termina con una situación que bordea el humor: "[...] para cambiar la conversación y decirle que sus encuentros eran lindos, pero que su citación no era del Petrarca sino de Metastasio, que yo acababa de leer. Esto, lejos de enfriarlo, lo ligó más a mí concediéndome mayor valor intelectual del que tenía" (123). Frecuentemente, cuando se refiere a las tertulias de su temprana infancia habla con admiración y atracción de la elocuencia e inteligencia que transmitían estos hombres a través de sus palabras 9 . Es por ello que durante ese periodo se dedicó a leer y a cultivarse intelectualmente, para así no decepcionar a su amado. Este cortejo amoroso -e intelectual- implicó formas de hacerse agradable al otro, y ella al ya conocer las reglas de sociabilidad y seducción, se centró en encontrar las tácticas y estrategias para seducir al joven médico ya no solo desde los sentidos, sino que a través de su intelecto.

En el rito de los amantes es importante mostrarse, pero también ocultar y Martina debía (de)mostrar sus conocimientos a través de las lecturas que compartían, pero a la vez ocultaba las posibles fallas que se podían develar ante los ojos de Augusto. Un ejemplo de esta estrategia de ocultamiento es el momento en que el enamorado le entrega un libro en francés - del autor Edgar Quinet-, idioma que ella desconocía. Para no decepcionarlo ella decide pedirle

\footnotetext{
${ }^{9}$ Cuando describe las tertulias de su tío refiere el gusto de escuchar a algunos de esos respetables invitados, refiriendo al "atractivo de la elocuencia" (60), incluso cuando su participación en estas instancias era lateral, por lo que señala: “[...] no puedo decir en verdad, que entonces conocí a esos caballeros, solamente los vi y oí" (61). La prevalencia que otorgará a la elocuencia la reafirmará cuando señala que la principal virtud que encuentra en el sexo opuesto refiere a este aspecto: "[...] la única aspiración de mi vida era encontrar un hombre que me cautivara por su talento que era lo que más admiraba" (92).
} 
a su hermano Manuel que le tradujera fragmentos que seleccionó: "[...] con esa adivinación tan femenina, [ya que] comprendía que era la que encuadraba con mi carácter y mi situación" (124). Aquí observamos dos tácticas, primero la lectura mediada por su hermano -lector-traductor cómplice-, pero también por la selección a través de la intuición, que da frutos a partir del análisis de esta obra fragmentaria. La mentira que construye Barros para conservar la misma valía intelectual, se verá desafiada, pues Augusto al ver cuán interesantes eran sus ideas, le entrega otro libro en francés -Contemplaciones de Víctor Hugo-, desafío al que responde Martina estudiando el libro y el idioma: "[...] sin más auxilio que un Ollendorf y un diccionario" (124). Aprendió el idioma y lo dominó en poco tiempo, atribuyendo al estado de enamoramiento sus deseos de aprender: "[...] iqué tanto puede el amor en el alma de una mujer que ama!" (125). Con esto encantó a su enamorado y logró abrir una nueva puerta hacia sus aprendizajes, pues al conocer este nuevo idioma pudo ingresar a una serie de nuevos textos: "[...] cuando ya pude leer en francés mi gran entusiasmo fué Lamartine, Graciela, Jocelyn, sus Poesías y sus Confidencias me hicieron encontrar, en él un afecto tan hondo que cifraba mi mayor dicha" (125). Luego continuará con Chateaubriand, Madame de Staël y Madame de Sevigné, de quienes devorará su obra. En este enamoramiento de la literatura francesa hay una pausa, y será otro regalo de Augusto el que la despegará de sus 'nuevos amantes':

Un buen día Augusto me regaló las Obras de Shakespeare con una preciosa dedicatoria que dice: Hay libros cuyas hojas, como las de la siempreviva, nunca mueren; éste es de esos libros, emblema de mi pensamiento, recuerdo de mi amistad. Febrero de 1869. No tengo para qué agregar que el atractivo de esas obras superó al de todas las demás y que este libro ha sido el fiel compañero de mi vida entera, hasta ser el inspirador de uno de mis primeros trabajos literarios (125-126).

Shakespeare y este libro son una forma de representación especular de lo que piensa Augusto Orrego Luco, es por esto que, al verse seducida por la literatura de los escritores franceses, él interrumpe el cortejo encausando su atención hacia su figura metonomizada en Shakespeare. No podemos olvidar el tono sugestivo y también político que se le atribuía a la literatura francesa 
durante este tiempo, por lo que el guía conduce nuevamente sus gustos a través de la introducción de este autor canónico, que está institucionalizado y validado plenamente por el elenco letrado masculino. Como afirma Roger Chartier en Cultura escrita, literatura e historia: "La lectura es un vehículo que impone autoridad" (2006: 27) y en el caso de los dos amantes, la lectura de Shakespeare impone la autoridad de este autor, pero a su vez la del crítico que tiñe al libro -y lo interviene- con sus ideas al señalar que lo identifica plenamente. El ejercicio de la dedicatoria es una recomendación, pero también una manipulación del texto que sirve para conquistar a Martina, pues ella no solo lee el libro, sino que se lo apropia de tal forma que lo hace piedra fundacional de su escritura crítica. Ella, posteriormente, dictará charlas sobre Shakespeare en clubes femeninos ${ }^{10}$, lo que permitirá que otras ávidas lectoras conozcan a este autor, pero ya mediado por la representación que hizo Augusto y la que construyó la misma autora.

Ya casados existirán mayores tensiones con respecto a los modos de regular los gustos de Martina, siendo el esposo quién disciplina a través de la escritura y la vigilancia ciertas conductas que pudiesen parecer perniciosas. Interesante es lo que ocurre cuando una famosa compañía de opereta llega a Santiago, donde actuaba Adelaida Ristori. Orrego, primero, decide pronunciarse negativamente en torno a estas manifestaciones culturales:

Por ese entonces vinieron a Santiago las primeras compañías francesas de opereta $\mathrm{y}$, tanto las piezas como su representación misma, causaban grán escándalo y, por lo mismo, atraían numeroso público. Augusto condenó la vida entera esa clase de representaciones y, como además quería evitar que yo me aficionase a esa clase de espectáculos que consideraba perniciosos, escribió artículos, en la prensa diaria sobre el Alcázar Lírico (128).

El esposo más que condenar la afición de Martina a este tipo de representaciones, decide traducir su molestia al código escrito, incorporando en su repudio a todos los posibles receptores de las operetas. Ella al leer

\footnotetext{
${ }^{10}$ Como ya señalamos el Club de Señoras leyó un trabajo sobre el problema de la autoría en Shakespeare llamado: "Francis Bacon era el verdadero autor del teatro shakesperiano" (292). Esta acción que atenta en contra de la autoría/autoridad será un gesto de empoderamiento el que traficará hacia las participantes de este club.
} 
esos escritos comprendió el porqué del acto censor y acepta las razones de la negativa. Como señala la misma Martina: “[al ser] médico y ya muy preocupado del estudio de las enfermedades nerviosas, no me llevaba a las [obras] excesivamente fuertes como 'Fedra' por miedo a que pudiesen hacerme mal a mí y al hijo que se anunciaba" (145). En esta restricción, por la salud de esta madre e hijo, él ejerce su conocimiento médico en tanto biopoder, disciplinando el cuerpo y reprimiendo reacciones inadecuadas para una mujer, sobre todo embarazada. Ella debe conformarse con ver algunas obras de Giacometti y Pia de Tolomei, obra que en palabras de la autora: "[...] la Ristori nos presentaba el modelo hermoso y grato de la fidelidad conyugal más excelsa" (145). A diferencia de la posible nocividad que encontraría en el texto Fedra (una imagen transgresora de feminidad) en Pia se escenifica una mujer sumisa, abnegada, que luego de todas las desconfianzas que padece a manos de Ghino y Nello, perdona a su esposo en el lecho de muerte. Orrego regula el cuerpo de Barros -ahora es su esposo, tiene el poder para realizarlo- y, a su vez, tiene el capital institucional que lo valida como un sujeto que tiene todo el 'derecho' para poner los límites a lo que puede ver y conocer. Esta tensión entre lo que Martina quiere y lo que Augusto le permite se tornará más latente durante el matrimonio, lo que se acentúa luego de la llegada de su hija:

[...] no tuve más que ella a quien dedicarle todas mis atenciones, pero pronto creció y me quedaba mucho tiempo para leer, en mis horas de soledad, y para la charla nocturna tan de mi agrado. Siempre he considerado que el día es para los demás y la noche es mía, por eso la destinaba para darme gusto (136).

El espacio intelectual está constreñido debido a su labor de madre, la que limita sus tiempos de ocio, situación que se revertirá solamente en el momento en que su hija crece y tiene una relativa autonomía -no es total pues en el día debe seguir sirviendo al rol de madre que asumió y no cuestiona-. Roger Chartier establece que para las lectoras, sobre todo aquellas que cumplen roles domésticos, la lectura es un acto subversivo, pues: “[...] la lectora se sustrae de este orden hogareño, de la dominación masculina, de las tareas domésticas" (2006: 143). El ejercicio lector en el caso de Barros, a su vez es altamente sugestivo producto de estas 'nocturnas evasiones' que realiza 
mientras el esposo duerme.

En esta tensión entre sumisión y transgresión se verán marcadas las representaciones de las prácticas de lecturas de Martina y aunque ella indica que el apoyo de su esposo fue trascendental en su formación (como) intelectual, sobre todo durante el periodo de cortejo, se trazarán líneas de fuga que intentarán escapar de los márgenes del deber ser femenino, siendo la lectura unos de estos puntos de escape.

\section{Conclusiones}

Sin duda que la experiencia de formación intelectual de Martina Barros es anómala para las mujeres de su tiempo y país, pero ello no quita el valor que el estudio de su trayectoria inicial de lectora no tenga implicancias para otras experiencias lectoras femeninas. Como señala Rossi Braidotti, recordando los casos de otras 'privilegiadas' -Virginia Woolf y de Simone de Beauvoir-: “[...] la categoría Mujer, pese a las diferencias que ciertamente existen entre las mujeres individuales, se identifica claramente como una categoría signada por supuestos comunes culturalmente impuestos. Por muy diferentes que sean en otros aspectos, todas las mujeres se hallan excluidas" (2004: 12). Esta representación constituye la negación de la subjetividad de las mujeres, y el resultado de ello es su exclusión de la vida política e intelectual. Es en este sentido que la autofiguración de Barros cobra relevancia para todas, pues más allá de sus privilegios constituye una voz que funciona como índice de las tensiones y complejidad que implicaba ser mujer letrada y, por lo tanto, de los problemas de expresar la subjetividad femenina en el contexto nacional durante la segunda mitad del siglo XIX y la primera del XX. Esa subjetividad se manifiesta en la selección -el 'encuadre'- con el que recuerda y narra la historia de otros y la suya propia, obligándonos a mirar 'los hechos' con otros ojos. A su vez, es en el relato y las acciones de estas pioneras que podemos rastrear esos movimientos vanguardistas que permitieron el ingreso de otras mujeres, menos privilegiadas, y que comenzarán a cobrar relevancia en las primeras décadas del $\mathrm{XX}$. La resistencia al status quo termina rindiendo frutos, por lo que no nos parece raro el rol que cobrará la figura de Barros en 
el movimiento feminista de comienzos del siglo XX. Ella será trampolín, pero a la vez bisagra de una época, permitiendo que otras se apropien de los lugares que fue cimentando en el tiempo y con sus prácticas. Entre ellas, la lectura como ejercicio subversivo que le permitió divulgar conocimientos que para otras estaban vedados a la vez que le permitió hablar más allá del mutismo que fingía tener.

\section{Referencias}

Amaro, L. "Encuadres de la memoria: Cartografías y genealogías en los textos de Martina Barros e Inés Echeverría". En: Anales de Literatura Chilena, 19, Junio 2013: 137-157.

Barros, M. Recuerdos de mi vida. Santiago: Orbe, 1942.

Prólogo a La esclavitud de la mujer (estudio crítico por Stuart Mill). Santiago: Palinodia, 2009.

Braidotti, R. "El sujeto en el feminismo". En: Feminismo, diferencia sexual y subjetividad nómade. Amalia Fischer Pfeiffer (Ed.). Barcelona: Gedisa, 2004: 9-25.

Castillo, A. "Estudio Preliminar. Las aporías de un feminismo liberal: Martina Barros traductora de Stuart Mill". En: Alejandra Castillo (Ed.) Martina Barros. Prólogo a La Esclavitud de la Mujer (Estudio crítico por Stuart Mill). Santiago: Palinodia, 2009: 7-36.

Certeau, M. de. La Invención de lo cotidiano. 1. Artes de hacer. México: Universidad Iberoamericana, Instituto tecnológico y de estudios superiores de occidente, 2007.

Chartier, R. Cultura escrita, literatura e historia. México: Fondo de Cultura Económica, 2006. 
Contreras, J. "La resistencia al libro. Mujeres, escritura y exclusión en el siglo XIX en Chile". En: Vestigios y especulación. Textos anunciados, inacabados y perdidos de la literatura chilena. Nibaldo Acero, Jorge Cáceres y Hugo Herrera (Eds.). Santiago: Chancacazo, 2014.

Egaña, M. L. La educación primaria popular en el siglo XIX en Chile. Santiago: LOM, 2000.

Landeros, D. "Avatares de una pionera: tensiones en(tre) las prácticas de escritura de Martina Barros". En: Contreras, Joyce, Damaris Landeros y Carla Ulloa. Escritoras chilenas del siglo XIX. Su incorporación pionera en la esfera pública y el campo cultural. Santiago: Ril, 2017: 153: 175 .

Littau, K. Teorías de la lectura. Libros, cuerpos y bibliomanía. Buenos Aires: Manantial, 2008.

Molloy, S. Acto de presencia. La escritura en Hispanoamérica. México: Fondo de Cultura Económica, 2001.

Miraux, J. P. La autobiografía. Las escrituras del yo. Buenos Aires: Nueva Visión, 2005.

Traverso, A. "Primeras escritoras en Chile y autorización del oficio literario". En: Anales de literatura chilena, 17, Junio de 2012: 61-80.

Vicuña, M. La belle époque chilena. Alta sociedad y mujeres de elite en el cambio de siglo. Santiago: Sudamericana, 2001. 